\title{
PRODUÇ̃̃ DO CONHECIMENTO NA UNIVERSIDADE PÚBLICA NO BRASIL: TENSÕES, TENDÊNCIAS E DESAFIOS
}

\author{
João Ferreira de Oliveira" \\ Universidade Federal de Goiás (UFG), Goiânia - GO, Brasil \\ Karine Nunes de Moraes** \\ Universidade Federal de Goiás (UFG), Goiânia - GO, Brasil
}

RESUMO: O texto analisa tensões, tendências e desafios da expansão e da produção do conhecimento nas universidades brasileiras, considerando as transformações no capitalismo globalizado e nas políticas para pesquisa e pós-graduação no Brasil. O estudo mostra que essa produção se tornou uma questão de Estado, sobretudo a partir dos anos 1990, em face da necessidade de aumento da competitividade empresarial e do país no cenário da globalização produtiva. A consolidação da pós-graduação, a criação dos fundos setoriais, assim como a ampliação do financiamento têm contribuído fortemente para a ampliação da produção de conhecimento, como evidenciam os indicadores sobre a produção científica do Brasil. Nesse contexto, o estudo aponta para mudanças significativas nas políticas, na expansão e na geração do conhecimento, especialmente em termos dos fins e do modus operandi da universidade e do trabalho acadêmico.

Palavras-chave: Produção do conhecimento. Pós-graduação. Políticas de ciência, tecnologia e inovação.

\section{KNOWLEDGE PRODUCTION IN PUBLIC UNIVERSITY IN BRAZIL: TENSIONS, TENDENCIES AND CHALLENGES}

ABSTRACT: This paper analyzes the tensions, tendencies and challenges of the expansion and knowledge production in Brazilian universities, considering the changes in the global capitalism and in the policies for research and postgraduate studies in Brazil. The study shows that this production has become a matter of State, especially since the 1990s, due to the need to increase business and the country's competitiveness in the productive globalization scenario. The consolidation of postgraduate education, the creation of sector funds, as well as the expansion of funding for research,

http://dx.doi.org/10.1590/0102-4698161626

- Doutor em Educação pela Universidade de São Paulo (USP) e Professor da Universidade Federal de Goiás (UFG). Pesquisador do CNPq. E-mail: < joao.jferreira@gmail.com>.

"*Doutora em Educação pela Universidade Federal de Pernambuco e Professora da Faculdade de Educação da UFG. Email: < karine.ufg@gmail.com>. 
has strongly contributed to the expansion of knowledge generation, as the indicators about Brazilian scientific production has evidenced. In this context, the study points to significant changes in the educational policies, expansion and knowledge generation, especially in terms of the objectives and the modus operandi of the university and the academic work.

Keywords: Knowledge production. Post graduation. Science and technology policies.

\section{INTRODUCุ̃̃O}

O presente texto analisa tensões, tendências e desafios da expansão e da produção do conhecimento nas universidades e instituições públicas de pesquisa no Brasil, considerando as transformações no capitalismo globalizado nas políticas e marco legal na área de Ciência, Tecnologia e Inovação (CT\&I), educação superior, pesquisa e pós-graduação no Brasil. O estudo mostra que essa produção se tornou uma questão de Estado, sobretudo a partir dos anos 1990, em face da necessidade de aumento da competitividade empresarial e do país no cenário da globalização produtiva. A expansão da educação superior, a consolidação da pós-graduação, a criação dos fundos setoriais, assim como a ampliação do financiamento para a pesquisa têm contribuído fortemente para a ampliação da produção do conhecimento, como evidenciam indicadores da pós-graduação, da internacionalização e da produção científica do Brasil. Nesse contexto, o estudo aponta para mudanças significativas nas políticas, na expansão e na geração do conhecimento, especialmente em termos dos fins e do modus operandi da universidade pública e do trabalho acadêmico. $\mathrm{O}$ estudo examina, inicialmente, a centralidade do conhecimento, das tecnologias e da inovação no contexto do capitalismo globalizado e, em seguida, trata das tensões e perspectivas das políticas e marco legal para a expansão da produção do conhecimento no Brasil.

\section{A CENTRALIDADE DO CONHECIMENTO, DAS TECNOLOGIAS E DA INOVACุÃO NO CONTEXTO DO CAPITALISMO GLOBALIZADO}

O capitalismo, no atual contexto da globalização econômica, constitui-se em um sistema-mundo de acumulação de capital produtivo e financeiro ${ }^{1}$. O mundo encontra-se cada vez mais articulado por um complexo sistema de relações de produção, de forças produtivas, de produção de mercadorias e de trocas econômicas que implica em um processo de exploração do trabalho e de produção de 
mais-valia, ou melhor, de valorização do capital em escala mundial (WALLERSTEIN, 2001; CHESNAIS, 1996; HARVEY, 1994). A mundialização do capital se dá, em parte, pelos investimentos das multinacionais ou oligopólios em outros países, o que gera uma maior integração e internacionalização do capital produtivo. De outra parte, isso tem permitido uma maior conexão da esfera financeira ou monetária, que se autonomiza cada vez mais em relação ao capital industrial ou produtivo (CHESNAIS, 1996, 1998).

As estratégias dos países ricos, dos organismos multilaterais e das grandes empresas globais para essa livre circulação do capital produtivo e financeiro se estruturaram mais fortemente a partir do final dos anos 1970 com a difusão do neoliberalismo como "caminho único" para a superação da crise vivenciada pelo capitalismo. O neoliberalismo estabeleceu, pois, as bases ideológicas para a globalização da sociedade de mercado, com a consequente desconstrução do Estado de bem-estar social, fundamentando, assim, as alterações nos estados-nação, nas economias nacionais e nos organismos multilaterais, no sentido de criar as condições para a acumulação flexível em âmbito mundial (HARVEY, 1994).

Harvey (1994) afirma que as transformações políticas e econômico-produtivas, sobretudo desde os anos 1970, tem promovido modificações radicais nos processos de trabalho, nos hábitos de consumo, nas configurações geográficas e geopolíticas e nos poderes e práticas do estado. Trata-se da constituição de um novo regime de acumulação, associado a um novo modo de regulamentação política e social, que busca compatibilizar o sistema e equacionar a crise do capital. Segundo esse autor, no entanto, "a produção em função de lucros permanece como princípio organizador básico da vida econômica" (HARVEY, 1994, p. 117), em que pese a condição pósmodern $a^{2}$ que temos vivenciado na contemporaneidade.

Nesse contexto, o avanço da ciência e do conhecimento permitiu uma conexão ainda maior entre países ricos e pobres, de modo a ampliar a mais-valia relativa e a autonomia da esfera financeira. O controle dos processos de trabalho e dos de produção e consumo demanda e incorpora, incessantemente, tecnologias e inovações, em face da integração econômica e da competitividade mundial. Os mercados têm contribuído para a maior flexibilização dos processos de trabalho, para a mobilidade geográfica e para rápidas mudanças nas práticas de consumo (HARVEY, 1994). O mundo do trabalho, sobretudo na alta esfera da produção, passa a demandar, incessantemente, mudanças na organização desse e da atividade profissional, sobretudo em termos de flexibilidade, polivalência e 
novas competências, o que significa maior exigência de qualificação da força de trabalho, além de sistemas de inovação permanente.

Esse modo de acumulação flexível do capital tem sido devastador para as condições de vida no planeta, uma vez que intensifica a produtividade e o consumo de matérias brutas e primas, com a sofisticação dos meios de produção e consumo, promovendo a intensificação do aquecimento global e o esgotamento dos recursos naturais (RIFKIN, 2003). Além disso, observa-se que a força de trabalho se complexifica, pois há, por um lado, processos que levam à sua constante diminuição e degradação e, por outro, processos que implicam na exploração acentuada das capacidades intelectuais e subjetivas dos trabalhadores, sobretudo os mais qualificados (HELOANI, 2003).

O modo de organização e controle do trabalho mudou consideravelmente desde a administração científica de Taylor (1990). A gerência científica, antes interessada em racionalizar e intensificar o trabalho, separando concepção e execução, busca agora, cada vez mais, aumentar a eficiência e a produtividade por meio da captura das forças e capacidades criativas do trabalhador (CATTANI, 2008). Para tanto, trabalha no sentido de obter a sua adesão, incorporando-o na coordenação do esforço coletivo de produção. Assim, o controle do capital sobre o trabalho está cada vez mais dentro do próprio processo de trabalho, com a vigilância, internalização e cooperação dos próprios trabalhadores. A subordinação real do trabalho ao capital passa a ocorrer mais intensamente com a conivência dos trabalhadores (HELOANI, 2003; RIFKIN, 1995; BRAVERMAN, 1987).

De acordo com Wallerstein (2001), o capitalismo como economia-mundo vem acentuando: a) a constituição de um estado global, marcado pelos interesses dos países ricos (hegemonia dos estados fortes), dos organismos multilaterais e dos grandes oligopólios; b) a autonomização das altas finanças em relação ao sistema produtor de mercadorias; c) a divisão do trabalho entre regiões (centro, semiperiferia e periferia). $O$ resultado tem sido uma mercantilização e mercadorização das coisas, do conhecimento, inclusive do trabalho humano e dos diferentes processos sociais. Tudo se torna mercadoria e adquire valor de troca determinado no mercado global.

A ideologia do livre mercado ou a crença fundamentalista na mão invisivel do mercado ${ }^{3}$ como portadora de todas as virtudes do crescimento econômico e das liberdades individuais e coletivas, está na base da regulamentação do estado global por meio dos organismos multilaterais como o Fundo Monetário Internacional (FMI), a Organização Mundial do Comércio (OMC) e o Banco Mundial 
(BM). As regras básicas, as medidas ou as "políticas corretas" do neoliberalismo adotadas desde o Consenso de Washington ${ }^{4}$, em 1989, e difundidas mundo afora foram, sobretudo: a austeridade fiscal, a privatização, a liberação dos mercados (comércio e finanças), o enfraquecimento dos estados-nação, a garantia dos direitos de propriedade e a focalização dos investimentos públicos, que abriram as fronteiras para o investimento estrangeiro direto para as grandes corporações, assim como para a expansão da esfera financeira e flexibilização do mercado de trabalho. Nessa lógica, desde o final dos anos 1970, os estados-nação e os governos deveriam assumir funções mínimas do ponto de vista de sua atuação ou intervenção na esfera econômica, abrindo caminho para a livre iniciativa e para os interesses do capital (STIGLITZ, 2002; DUPAS, 2005).

A flexibilização do mercado de trabalho tem se intensificado e se agravado nas últimas décadas, tendo por base o que Rifkin $(1995,2001)$ chama de o "fim dos empregos", associado a "era do acesso" no âmbito do capitalismo. Para ele, em decorrência dos avanços tecnológicos, organizacionais e da autonomação, está ocorrendo uma crescente substituição do trabalho humano global, ou melhor, um declínio sistemático e inevitável dos empregos em escala global em todos os setores (agricultura, indústria e serviços). Assim, mesmo com o surgimento de algumas novas funções ou empregos, o desaparecimento de diversas funções e postos de trabalho tem sido uma constante. Ele entende que há dois tipos de ocupações ou empregos surgindo, mas que não resolvem o problema do desemprego estrutural ou tecnológico: os de baixa remuneração e temporários e os das altas esferas de comando da produção, para os chamados "trabalhadores do conhecimento", que decorrem do fato do conhecimento se constituir num setor emergente.

Nesse contexto, Santos (1997) entende que está em curso uma mundialização do espaço geográfico, ou seja, uma economia mundializada ou globalizada, cuja base é a ciência, a tecnologia e a informação. A globalização do tempo-espaço na lógica capitalista está criando uma ordem racional, funcional, ou melhor, uma natureza instrumentalizada segundo os interesses do capital. Assim o meio técnico-científico-informacional vem sendo produzido em função dos interesses da mais-valia mundializada, em conformidade com a lógica e os interesses do capital. Nesse contexto, intensificase, cada vez mais, a unificação da natureza na lógica mercadológica que acentua a fluidez, a competitividade e a racionalidade privada. A vida passa a estar subordinada e comandada paulatinamente pelos sistemas técnicos e pela lógica que os orienta. 
Neste sentido, o conhecimento, a pesquisa e a inovação assumem uma perspectiva mais racionalizadora e interessada no sentido capitalista (SANTOS, 1997). Os produtos e processos acadêmicos só passam a ganhar sentido se contribuírem para a competitividade e o lucro das empresas. Ocorre que o sistemamundo representado pela globalização tem funcionalizado o espaço geográfico e a formação do meio técnico científico informacional em favor dos países ricos, das instituições supranacionais ou empresas multinacionais. A chamada "economia do conhecimento" representa em larga medida esse novo sistema social hegemônico, com objetos e relações cada vez mais mundializadas. Esse novo sistema, que conta com uma unidade de comando orientada pela intencionalidade mercantil, vai sendo imposto de modo a promover uma universalidade e unificação simbólica e material.

As contradições desse sistema de acumulação de capital, com forte base na produção de conhecimentos, tecnologias e inovação, se evidenciam destacadamente por meio do aquecimento global, da eliminação dos postos de trabalho, do surgimento de movimentos anti-sistêmicos, do aumento da fome e da miséria, da violência urbana, dentre outros. Essa crise estrutural, reflexo das contradições internas do capitalismo, segundo Wallerstein (2001), pode nos conduzir a uma bifurcação, ou melhor, à transição para uma nova ordem ou novo sistema, qual seja: uma democracia ou sociedade mais igualitária ou um sistema desigual-desumano, polarizado-explorador, com características do autoritarismo feudal e do fascismo. Urge, portanto, outro modo de pensar as relações de produção e de utilizar as forças produtivas a favor da vida humana, da cidadania coletiva e da preservação do planeta, o que certamente passa pela produção do conhecimento, das tecnologias e da inovação numa lógica emancipadora.

\section{AS POLÍTICAS E O MARCO LEGAL PARA A EXPANSÃO DA PRODUÇÃO DO CONHECIMENTO NO BRASIL: TENSÕES E DESAFIOS}

É nesse contexto de acumulação e de contradições da economia capitalista globalizada que a inovação para a competitividade empresarial e para o desenvolvimento vem se constituindo como paradigma, estratégia e agenda para as políticas públicas no Brasil, especialmente nas áreas de ciência, tecnologia, pesquisa e educação. As reformas fundadas na lógica da chamada economia do conhecimento, competitividade, produtividade e parcerias públicoprivadas têm sido uma constante do Estado brasileiro desde os anos 1990, independentemente da orientação político-partidária, como 
evidenciam os marcos legais constituídos, o padrão de financiamento adotado, as parcerias em curso e as articulações entre mundo empresarial, agências de fomento e mundo acadêmico (OLIVEIRA; AMARAL, 2012; OLIVEIRA; AMARAL, 2013; OLIVEIRA; MORAES; FERREIRA, 2015).

As análises das políticas em curso mostram que a produção do conhecimento se tornou uma questão de Estado sob o discurso da necessidade de aumento da competitividade das empresas e do país no cenário da globalização produtiva. Alianças estratégicas para a produção de conhecimento, em termos de processos e produtos, são vistas como fundamentais para alcançar tal objetivo. Nesse sentido, uma das estratégias adotadas tem sido o investimento em inovação tecnológica permanente, demandando maior aporte financeiro em pesquisa e tecnologia e parcerias entre governo, universidades e institutos de pesquisa, públicos e privados. (SGUISSARDI; SILVA JÚNIOR, 1997; CATANI; OLIVEIRA, 2015).

A materialidade desse discurso vem se estabelecendo nas políticas, marcos legais e políticas governamentais que buscam ampliar as parcerias público-privadas, conjugando, por meios e recursos diversos, os interesses privados no âmbito do estado e da esfera pública. Ações governamentais, sobretudo no domínio da ciência e tecnologia, evidenciam cada vez mais uma indiferenciação entre os interesses públicos e privados. Esses indistintos limites estão se ampliando na produção do conhecimento e, especialmente, na sua apropriação e utilização. Esse direcionamento está em sintonia com o que defendem os arautos da chamada terceira via ao proporem uma economia mista com equilíbrio entre governo, mercado e sociedade civil (GIDDENS, 2001; BRESSER PEREIRA; WILHEIM; SOLA, 1999), com ampliação do espaço público não-estatal mediante produção de serviços e mecanismos de controle baseados em princípios, estratégias, gestão e práticas privadas.

Nesse contexto, em 3 de agosto de 2011, o Ministério da Ciência e Tecnologia (MCT) passou a chamar-se Ministério da Ciência Tecnologia e Inovação (MCTI), o que simbolicamente concretiza o movimento de afirmação da política de inovação para a competitividade e desenvolvimento que vinha se institucionalizando desde a criação dos fundos setoriais a partir do final dos anos $1990^{5}$. Por sua vez, em 2015, foi aprovada a Emenda Constitucional nº. 85, de 26 de fevereiro de 2015, que alterou e adicionou dispositivos na Constituição Federal no que se refere ao tratamento das atividades de ciência, tecnologia e inovação (CT\&I). Já em 11 de janeiro de 2016, por meio da Lei nº 13.243/2016, ocorreu a aprovação do Marco Legal 
de CT\&I, que dispôs sobre estímulos ao desenvolvimento científico, à pesquisa, à capacitação, à inovação, alterando várias leis existentes e disciplinando os termos da Emenda Constitucional no. 85/2015.

Nesse contexto, o governo assume que o conceito de inovação tem

[...] permeado as ações ligadas à área de ciência e tecnologia, especialmente a partir da edição da Lei da Inovação ( $\mathrm{n}^{\circ}$ 10.973/2004), que trata de medidas de incentivo à pesquisa científica e tecnológica desenvolvidas no ambiente acadêmico e aplicadas às empresas; e da Lei do Bem (nº 11.196/2005) que prevê a concessão de incentivos fiscais às empresas que inovam (OLIVEIRA; AMARAL, 2012, p. 4). ${ }^{6}$

O artigo art. 218, nos termos da Emenda Constitucional $n^{\circ}$. 85/2015, estabelece que "O Estado promoverá e incentivará o desenvolvimento científico, a pesquisa, a capacitação científica e tecnológica e a inovação". Define ainda que "A pesquisa científica básica e tecnológica receberá tratamento prioritário do Estado" $\left(\mathbb{S} 1^{\circ}\right)$ e que cabe ao Estado apoiar "a formação de recursos humanos nas áreas de ciência, pesquisa, tecnologia e inovação" $\left(\$ 3^{\circ}\right)$. Todavia, a maior novidade desse novo marco legal se dá na forte interpenetração entre as esferas pública e privada. O $\$ 6^{\circ}$ afirma que o Estado deverá estimular "a articulação entre entes, tanto públicos quanto privados, nas diversas esferas de governo" (BRASIL, 2015). Nessa direção, o parágrafo único do art. 219 estabelece:

O Estado estimulará a formação e o fortalecimento da inovação nas empresas, bem como nos demais entes, públicos ou privados; a constituição e a manutenção de parques e polos tecnológicos e de demais ambientes promotores da inovação, a atuação dos inventores independentes e a criação, absorção, difusão e transferência de tecnologia. (BRASIL, 2015)

A inovação deve ocorrer, pois, nas empresas vinculadas ao ambiente de interesse do capital, especialmente das possibilidades e efetividades dos negócios, que assegurem maior competitividade empresarial. Nessa direção, os artigos 219-A e 2019-B da Emenda Constitucional $n^{\circ}$. 85/2015 acrescentam:

Art. 219-A. A União, os Estados, o Distrito Federal e os Municípios poderão firmar instrumentos de cooperação com órgãos e entidades públicos e com entidades privadas, inclusive para o compartilhamento de recursos humanos especializados e capacidade instalada, para a execução de projetos de pesquisa, de desenvolvimento científico e tecnológico e de inovação, mediante contrapartida financeira ou não financeira assumida pelo ente beneficiário, na forma da lei.

Art. 219-B. O Sistema Nacional de Ciência, Tecnologia e Inovação (SNCTI) será organizado em regime de colaboração entre entes, tanto públicos quanto privados, com vistas a promover o desenvolvimento científico e tecnológico e a inovação. (BRASIL, 2015) 
Como se vê, todos os entes federados devem cooperar com recursos financeiros e humanos especializados, bem como, com a capacidade instalada para promover a pesquisa, o desenvolvimento tecnológico e a inovação, tanto em entidades públicas como privadas. O desenvolvimento evocado nos textos legais está, pois, condicionado a esse esforço, sobretudo dos entes públicos, em tornar as empresas mais inovadoras e mais competitivas em âmbito global. Ademais, o regime de colaboração, antes uma prerrogativa dos entes públicos federados na garantia de serviços públicos, estende-se aos entes privados, visando ampliar produtos e processos que ampliem as vantagens competitivas das empresas.

Reafirma-se, desse modo, a crença na capacidade do mercado e na chamada economia do conhecimento em promover o desenvolvimento do país. Parece estar subtendido que crescendo a competitividade das empresas, por meio da inovação de produtos e processos, crescem o ambiente de negócios, o lucro e a acumulação de capital, as oportunidades de emprego e renda, de modo a trazer benefícios para a sociedade em geral. A função do estado passa a ser a de promover, por todos os meios e instrumentos de que dispõe, a transferência de conhecimento para as empresas ou, mais ainda, de realizar sua produção diretamente nas empresas, considerando as necessidades de inovação e competitividade. Nessa direção, busca-se realizar alterações na mentalidade e nas relações entre os agentes públicos e privados, institucionais ou individuais, sobretudo no modus operandi e no habitus daqueles que têm por ofício a geração de conhecimento novo, a exemplo das universidades públicas (OLIVEIRA; AMARAL, 2015).

Essa mudança na orientação constitucional está articulada à direção anteriormente estabelecida no Plano Plurianual (PPA) 20122015: Mais Brasil Mais Desenvolvimento, Mais Igualdade, Mais Participação ${ }^{7}$ e no Plano Brasil Maior (BRASIL, 2011) ${ }^{8}$. Esses dois documentos já traziam aspectos fundamentais do entendimento que balizariam as políticas, programas e ações no âmbito da CT\&I. De acordo com o PPA (2012-2015), as forças de mercado é que impulsionam e dinamizam o desenvolvimento, embora caiba ao Estado o papel de orientar e conjugar os meios e recursos do governo, do setor privado e da sociedade para esse fim ${ }^{9}$. Embora faça certa crítica ao fundamentalismo de mercado da visão neoliberal que resultou numa forte crise do capitalismo a partir do final do século XX (ANDERSON, 1999), reafirma-se a crença na sociedade de mercado, mas reconhece-se que este é imperfeito e que o Estado e os 
governos têm papel decisivo em sua potencialização, na reprodução do capital e no crescimento econômico (STIGLITZ, 2002).

Sob essa concepção foi criado o Programa Nacional de Aceleração de Startups (Start-Up Brasil) ${ }^{10}$, com a função de revitalizar o mercado continuamente e acelerar o desenvolvimento de empresas nascentes, sobretudo de base tecnológica, contribuindo, deste modo, para permear toda a lógica de estruturação, financiamento e ações na área de Tecnologia e Inovação. O Start-Up Brasil integra o Programa Estratégico de Software e Serviços de TI (TI Maior) que, por sua vez, é uma das ações da Estratégia Nacional de Ciência e Tecnologia e Inovação (ENCTI), que elege as tecnologias de informação e comunicação entre os programas considerados prioritários para impulsionar a economia brasileira. Entende-se que,

A competitividade global está cada vez mais acirrada. O desenvolvimento de novas tecnologias e modelos de negócios passa a ser fundamental para a disputa por mercados globais, trazendo imensos desafios para as empresas globais gerarem inovação no tempo da demanda de mercado. Neste contexto, o Brasil precisa construir ambientes propícios à aceleração do empreendedorismo de base tecnológica, alavancando a geração de bens e serviços inovadores com competitividade global. ${ }^{11}$

No Plano Brasil Maior (BRASIL, 2011) ${ }^{12}$, que estabeleceu as novas bases da política industrial, tecnológica, de serviços e de comércio exterior, o slogan é "Inovar para competir. Competir para crescer". Sob a responsabilidade do Ministério do Desenvolvimento, Indústria e Comércio Exterior, o Plano aponta, em sua dimensão sistêmica, para a promoção da inovação mediante o financiamento público e forte articulação com o setor privado. Pretende-se ampliar o financiamento público à inovação, destacadamente por meio do Banco Nacional de Desenvolvimento Econômico e Social (BNDES) e elevar o dispêndio empresarial em pesquisa e desenvolvimento (P\&D) no país, considerado muito baixo para os padrões internacionais. $\mathrm{O}$ incentivo à inovação, sobretudo em áreas tecnológicas avançadas, se fará presente, conforme o Plano, em várias políticas e ações do governo, por meio de diferentes ministérios e regulamentações.

Segundo Oliveira e Amaral (2012, p. 5)

A análise das políticas, dos planos, programas, ações e, também, da regulamentação na área de P\&D e CT\&I mostram que o governo federal entende, por um lado, que os produtos e processos inovadores gerem impactos importantes nas cadeias produtivas inteiras, agregando valor aos produtos, racionalizam os processos de produção, produzem riqueza, distribuem renda, geram empregos e transformam o país, além de compreender que a pesquisa científica e tecnológica é base para a inovação e para a formação de recursos humanos qualificados. Por outro lado, tendo 
em vista inserir o Brasil no cenário internacional em igualdade de condições com as nações desenvolvidas, o governo federal estabelece como desafios: a) ampliar a taxa de inovação para melhorar os índices sociais; b) intensificar o desenvolvimento científico e tecnológico; c) aumentar os recursos públicos e privados nessa área.

Observa-se, pois, que as políticas e o financiamento de P\&D e CT\&I no Brasil se configuram cada vez mais como uma política de Estado, especialmente a partir da criação dos fundos setoriais ${ }^{13}$, no final dos anos 1990 (SANTOS; MORAES, 2010), 2010). Visando contribuir para a construção de uma política nacional de CT\&I de longo prazo, se caracterizando, em última instância, como uma obra de engenharia financeira, reformulando a estrutura de financiamento de C\&T (PACHECO, 2003), e, engendrando, assim, uma nova modalidade de organização da política nacional de CT\&I, ao estabelecer um padrão de financiamento a longo prazo e o estímulo à participação do setor privado e sua interação com universidades e institutos de pesquisa (SANTOS; MORAES, 2010).

A partir desse novo cenário, o país ganhou, na área de P\&D e CT\&I, um impulso sem precedentes, que pode ser percebido não somente na ampliação do aporte de recursos do MCTI, mas, também em indicadores relativos à produção do conhecimento nesse mesmo período. Já na primeira década do ano 2000, o recurso investido em bolsas pelo CNPq passou de $\mathrm{R} \$ 411$ milhões para $\mathrm{R} \$ 806$ milhões em 2010, o que representa um aumento de cerca de 96,10\%. Na Capes o montante de recursos para bolsas passou de $\mathrm{R} \$ 403$ milhões para $\mathrm{R} \$ 1,829$ bilhões, o que representa um acréscimo superior a 353,84\%. Quanto à produção científica, o Brasil passou a responder por cerca de 2,29\% da produção científica mundial, sendo que essa participação dobrou entre os anos de 2000 e 2009. Nesse mesmo período, o número de publicações aumentou cerca de $205 \%$, alcançando a marca de 32.100 artigos indexados no Institute for Scientific Information (BRASIL, 2010). No período de 2000 a 2014 o número de programas de pós-graduação passou de 1.440 para 3.678, o número de projetos de pesquisa chegou a 41.539, o número de grupos de pesquisa saltou de 2.412 para 35.424 e o fomento à pesquisa do CNPQ passou de 115.797 milhões para 519.732 milhões em 2013. ${ }^{14}$

Todavia, Peixoto (1994), em sua tese de doutorado sobre o processo de formação do pesquisador no Brasil, evidencia que já no final dos anos 1960, durante o regime militar, as bases da política de ciência e tecnologia foram estabelecidas de modo articulado ao processo de estruturação, institucionalização e expansão da pós-graduação. Nesse contexto, foi idealizado um projeto de país pelos militares, assim como 
as bases tecnocráticas e o macro planejamento, incluindo a $C \& \mathrm{~T}^{15}$. Nessa direção, Alves e Oliveira (2014, p. 352) afirmam

\begin{abstract}
A pós-graduação no Brasil se estrutura intensamente a partir do Parecer $n^{\circ} 977$ CES/CFE, de 3 de dezembro de 1965, conhecido como Parecer Newton Sucupira, e da Reforma Universitária de 1968, quando educação e desenvolvimento econômico estão atrelados num projeto de governo dos militares que planejaram um modelo de ensino superior, de universidade e, consequentemente, de pósgraduação para atender a esse objetivo. O propósito era implantar e desenvolver o regime de cursos de pós-graduação no âmbito do ensino superior, uma vez que havia o entendimento de que faltava maior precisão no tocante à natureza dos cursos de pós-graduação então existentes no país. É, pois, nesse contexto do Regime Militar que a pós-graduação vivenciou um movimento de estruturação, normatização e institucionalização, bem como de ampliação do fomento, da expansão e da adoção de sistemática de avaliação, cujas diretrizes e bases permanecem ainda hoje.
\end{abstract}

A estruturação e expansão da pós-graduação, da pesquisa e da CT\&I foram sendo estabelecidas ao longo de décadas no Brasil. O financiamento público constante e a avaliação permanente de cursos e programas foram dois pilares da modelação e da consolidação da pesquisa e da pós-graduação no Brasil, assim como da criação e consolidação das agências de fomento federal, a exemplo da Finep, do CNPq e da Capes. Destacam-se ainda as Fundações de Apoio à Pesquisa criadas em muitos estados brasileiros e que, nas duas últimas décadas, têm procurado realizar uma gestão mais articulada com as agências federais, em conformidade com a política mais ampla do setor. Observa-se, portanto, a ampliação do processo de articulação das políticas e ações na área de CT\&I, pesquisa e pós-graduação induzidas pelo governo federal, que passou a adotar uma perspectiva mais sistêmica e com foco na competitividade das empresas em áreas consideradas estratégicas para o desenvolvimento, a articulação entre o setor público e privado, bem como a forte articulação entre universidades e demandas dos setores produtivos, sobretudo industriais, por inovação.

Esse movimento pode ser claramente visto no arcabouço legal para o setor, dentre eles: a) na Lei no. 11.196/2005, que institui o Regime Especial de Tributação para a Plataforma de Exportação de Serviços de Tecnologia da Informação (REPES), o Regime Especial de Aquisição de Bens de Capital para Empresas Exportadoras (RECAP) e o Programa de Inclusão Digital. Essa lei dispõe, pois, sobre incentivos fiscais para a inovação tecnológica, sendo mais conhecida como "lei do bem"; b) na Lei no. 10.168/2000, que institui contribuição de intervenção de domínio econômico destinada a financiar o Programa de Estímulo à Interação Universidade-Empresa para o Apoio à 
Inovação, "cujo objetivo principal é estimular o desenvolvimento tecnológico brasileiro, mediante programas de pesquisa científica e tecnológica cooperativa entre universidades, centros de pesquisa e o setor produtivo" (BRASIL, 2000); c) e, mais recentemente, na Lei $n^{\circ} .13 .123 / 2015$, que regulamenta a Constituição Federal, no que se refere ao acesso ao patrimônio genético, à proteção e acesso ao conhecimento tradicional associado e à repartição de benefícios para conservação e uso sustentável da biodiversidade.

Conforme Oliveira e Amaral (2012, p. 6),

Todas essas leis, articuladas aos programas e ações existentes, buscam eliminar a burocracia na área e ampliar os incentivos fiscais, além de fomento à inovação, à pesquisa científica e tecnológica e à interação universidade-empresa. Trata-se, pois, de ofertar crédito com juros baixos para inovação, ampliar a participação em fundos, incentivar empresas inovadoras, oferecer subvenção econômica para inovação e para incubadoras e parques tecnológicos, favorecer as compras governamentais na área assim como apoiar a P\&D nas empresas por instituições de pesquisa.

Contudo, a mudança mais substancial e mais recente na área foi a sanção da Lei nº 13.243/2016, aprovando o Marco Legal de Ciência e Tecnologia, ao dispor sobre estímulos ao desenvolvimento científico, à pesquisa, à capacitação, à inovação. Foram modificadas nove leis existentes, a saber:

a) Lei n. 10.973/2004, que dispõe sobre incentivos à inovação e à pesquisa científica e tecnológica no ambiente produtivo;

b) Lei n. 6.815/1980, que define a situação jurídica do estrangeiro no Brasil, e cria o Conselho Nacional de Imigração;

c) Lei n. 8.666/1993, que regulamenta o art. 37, inciso XXI, da Constituição Federal, instituindo normas para licitações e contratos da Administração Pública;

d) Lei n. 12.462, que institui o Regime Diferenciado de Contratações Públicas (RDC);

e) Lei n. 8.745/1993, que dispõe sobre a contratação por tempo determinado para atender a necessidade temporária de excepcional interesse público, nos termos do inciso IX do art. 37 da Constituição Federal;

f) Lei n. 8.958/1994, que dispõe sobre as relações entre as instituições federais de ensino superior e de pesquisa científica e tecnológica e as fundações de apoio;

g) Lei n. 8.010/1990, que dispõe sobre importações de bens destinados à pesquisa científica e tecnológica; 
h) Lei n. 8.032/1990, que dispõe sobre a isenção ou redução de impostos de importação;

i) Lei n. 12.772/2012, que trata do ingresso e da estruturação do Plano de Carreiras e Cargos de Magistério Federal, superior, Ensino Básico, Técnico e Tecnológico.

Essas mudanças legais consubstanciam uma orientação em construção e consolidação, já há algumas décadas, que materializam a CT\&I como política de Estado. Nessa direção destacam-se as seguintes diretrizes: a) integração da política de CT\&I à política industrial; b) incentivo à inovação e à pesquisa científica e tecnológica no ambiente produtivo, com vistas à capacitação tecnológica; c) expansão da pósgraduação com ênfase nas áreas tecnológicas e engenharias, além de outras áreas prioritárias; d) interação entre universidades, governo e empresas no tocante à geração de tecnologias e inovação; e) estímulo à internacionalização e cooperação internacional; f) ampliação da competitividade dos setores produtivos via inserção tecnológica, inovação e produção de patentes; g) promoção de uma cultura da inovação e do empreendedorismo; h) produção do conhecimento no "chão da fábrica" ou transferência dos resultados das pesquisas da universidade para o setor produtivo; i) incentivos fiscais às empresas na geração de conhecimento; j) definição de áreas prioritárias para investimento público; 1) ampliação das relações entre as instituições públicas de pesquisa científica e tecnológica e as fundações de apoio; m) facilitação das importações de bens destinados à pesquisa científica e tecnológica e isenção ou redução de impostos de importação; n) mudanças nas carreiras docentes das instituições públicas para facilitar a articulação da produção ou transferência de conhecimento e inovação para as empresas (OLIVEIRA; AMARAL, 2012).

A Lei n ${ }^{\circ}$. 13.243/2016, que tramitou por vários anos no Congresso Nacional, aprovou um Marco Legal para a CT\&I. O Marco surgiu a partir da discussão de um Código Nacional da Ciência para incentivo a empresas e pesquisadores para desenvolvimento de CT\&I. ${ }^{16} \mathrm{O}$ objetivo era unificar a legislação existente em termos de conceitos; de flexibilizar as regras de compras e contratos por pesquisadores, universidades ou empresas; de desburocratizar o acesso a equipamentos e insumos; de garantir aos cientistas acesso ao patrimônio genético ${ }^{17}$; de aumentar a liberdade para a atuação dos pesquisadores, sobretudo daqueles com dedicação exclusiva nas universidades; de incentivar parcerias das universidades com empresas e ampliar o investimento público; e, de ampliar os incentivos às empresas que queiram promover a inovação. 
O Marco foi louvado pelo governo, por entidades como a Sociedade Brasileira para o Progresso da Ciência (SBPC) e a Academia Brasileira de Ciências (ABC) e por outros agentes do campo acadêmico. Na cerimônia para sua sanção, a então Presidenta da República, Dilma Rousself, afirmou que,

Duas certezas unem todos os presentes nesta cerimônia. A primeira é que o Brasil possui uma extraordinária capacidade, um imenso potencial de produzir conhecimento e que, infelizmente, ainda não tem se traduzido em idêntica capacidade de transformar esses conhecimentos em inovação produtiva integralmente. A segunda é que em um ambiente regulatório e institucional mais favorável à cooperação entre universidades, laboratórios de pesquisa, governos, empresas, enfim, universidades, empresas e estados, nesse ambiente mais favorável transformaremos, certamente, mais ciência básica em inovação e transformaremos inovação em competitividade gerando um novo ciclo de desenvolvimento econômico no nosso País. ${ }^{18}$

Nesse discurso, a presidenta também ressaltou que o Marco Legal de CT\&I promove uma "reforma na legislação que regula a integração entre agentes públicos e agentes privados que integram nosso sistema de ciência, tecnologia e inovação" e que tratavase de dar "transparência, simplicidade e segurança jurídica a uma cooperação". Falou ainda que entendia que essa cooperação "é fundamental para o crescimento econômico, a geração de renda e emprego", de modo promover, "ao mesmo tempo, o desenvolvimento de forma sustentável, ampliando oportunidades para nossa população" (PORTAL PLANALTO, 2016). Desse modo, o Marco legal permitiria implementar o que previa a Emenda Constitucional $n^{\circ}$. 85/2015 e também complementaria a Lei de Inovação e a Lei do Bem, diminuindo "a distância entre produção de ciência e sua incorporação no ambiente produtivo (PORTAL PLANALTO, 2016). Fazendo referência, também, ao Plano Inova Empresa ${ }^{19}$, à criação da Associação Brasileira de Pesquisa e Inovação Industrial (Embrapii) $^{20}$, Organização Social, criada em 2013, com contrato de gestão junto ao MCTI, e à expansão e interiorização da rede federal de ensino técnico e de ensino superior. O propósito do Marco é contribuir para o "ciclo de transformação da ciência em tecnologia e inovação e em competitividade e desenvolvimento", numa "nova etapa na cooperação entre universidades, institutos de pesquisa, estado e empresas, cujos resultados serão mais oportunidades para nossa população e mais competitividade para o nosso país". ${ }^{21}$

Dentre os avanços do Marco Legal enfatizados pelo MCTI, pelo $\mathrm{CNPq}$, pela $\mathrm{ABC}$ e pela SBPC encontram-se ${ }^{22}$ : a introdução do conceito de capital intelectual; a ampliação do tempo máximo de 
trabalho dos professores das universidades federais, de 120 horas para 416 horas anuais ( 8 horas/semana), em programas ou projetos institucionais de ensino, pesquisa e extensão, ou em exercício de atividades de natureza científica e tecnológica dentro das empresas, contando com remuneração; o uso dos laboratórios universitários pelas indústrias para o desenvolvimento de novas tecnologias, com remuneração dos professores; a simplificação do processo de emissão de visto de trabalho para pesquisadores estrangeiros que vierem ao Brasil para participar de projetos de pesquisa; a simplificação das exigências burocráticas para licitação, a compra e importação de produtos destinados à pesquisa científica e tecnológica; a isenção e a redução de impostos de importação nas compras destinadas aos projetos de pesquisa, desenvolvimento e inovação; a nova visão sobre o papel da CT\&I, que "põe o Brasil realmente na rota da inovação" (PORTAL PLANALTO, 2016); a unificação da legislação, inclusive de conceitos dispersos; a permissão para que a União financie, faça encomendas diretas e até participe de forma minoritária do capital social de empresas, visando fomentar inovações e resolver demandas tecnológicas específicas do país.

A Lei no. 13.243/2016 prevê, ainda, que Instituições Científicas, Tecnológicas e de Inovação (ICT) poderão assinar acordos com empresas para o desenvolvimento de pesquisas conjuntas, podendo a ICT ceder ao parceiro privado a totalidade dos direitos de propriedade intelectual mediante compensação financeira ou não financeira, desde que economicamente mensurável. Em outras palavras, as empresas envolvidas nos projetos poderão manter a propriedade intelectual sobre os resultados (produtos) das pesquisas. Trata-se de um aspecto fundamental porque a patente ou a propriedade dos resultados ficava com a instituição pública e agora pode ficar com a empresa que pagou pela pesquisa. Outro destaque é que o Poder Público (União, Estados e municípios) pode fomentar diretamente a inovação tecnológica em empresas e ICTs, incluindo a contratação direta de projetos de pesquisa que envolvam risco tecnológico, para solução de problema técnico específico ou obtenção de produto, serviço ou processo inovador sem obrigatoriedade de licitação.

A aprovação do Marco legal não se deu sem resistências indicando claramente a existência de disputa de concepções de P\&D e CT\&I no campo. Um conjunto amplo de entidades científicas ${ }^{23}$ enviou carta à Presidenta da República, em 28 de dezembro de 2015, afirmando que o Projeto de Lei Complementar n ${ }^{\circ} .77 / 2015$, que deu origem à Lei $n^{\circ}$. 13.243/2016, era "uma ameaça sem precedentes às instituições públicas de ensino superior e de pesquisa, no Brasil" 
(ADUNICAMP, 2015, p. 1). Advogavam na Carta a realização de audiências públicas amplas para que todos os segmentos da comunidade acadêmica e de pesquisa fossem ouvidos. Finalmente, pediam que a Presidenta vetasse integralmente o Projeto. Para essas entidades, o Projeto de Lei Complementar nº. 77/2015 estabelecia diretrizes completamente privatizantes para as entidades públicas de pesquisa. Afirmavam que, se aprovado o projeto, a área pública de pesquisa no Brasil seria virtualmente sequestrada por interesses privados e vultosos recursos destinados pelo Estado seriam apropriados por interesses particulares. Além disso, ressaltavam que o Estado perderia o direito de autoria em caso de uma grande invenção ou descoberta cientifica, que passariam a ser revertidas para a empresa privada (royalties) e não para o bem da população.

Para essas entidades as consequências seriam:

- Aumento da sangria do fundo público para empresas privadas e a substituição de instituições públicas (estatais) de pesquisa por OS, apontando para drástica diminuição de concursos públicos para as carreiras de professores universitários e pesquisadores.

- Professores universitários e pesquisadores das instituições públicas (estatais) assumirão funções de diretores-presidentes de OS que desenvolvam atividades de pesquisa e inovação tecnológica, auferindo remuneração c/ou rendimentos pelas atividades desenvolvidas nos setores público e privado. Isso impactara negativamente o regime de trabalho de dedicação exclusiva nas instituições públicas de ensino superior.

- Professores e pesquisadores financiados com recursos públicos atuarão dentro de empresas privadas.

- O gasto total em P\&D (Pesquisa e Desenvolvimento) continuará a ser o mesmo ou poderá decair. Isso porque o Estado tende a manter ou ampliar seus gastos ao passo que as empresas tenderão a diminuí-los, uma vez que poderão ter acesso aos recursos estatais (financeiros e de pessoal).

- O número de patentes registradas pelas universidades deverá cair, pais o registro passara a ser feito em nome dos pesquisadores envolvidos no processo e das OS a que eles estarão ligados. A fonte dos recursos financeiros para a manutenção dos registros continuará a mesma, ou seja: os cofres públicos; enquanto a apropriação dos benefícios será privada.

- Ocorrerá uma restrição a divulgação pública dos resultados de pesquisa, em função do interesse na apropriação do conhecimento pelas organizações de caráter privado que coordenam os projetos. (ADUNICAMP, 2015, p. 1)

As entidades signatárias da Carta destacaram ainda que o PLC n ${ }^{\circ} .77 / 2015$ propunha a criação de ICT com o estatuto jurídico de Organizações Sociais para o desenvolvimento de atividades de pesquisa no Brasil e que eles poderiam: a) receber recursos públicos de todos os entes federados e de fundações ditas "de apoio" para a 
cobertura de todas as suas despesas; b) usufruir de recursos humanos especializados (pesquisadores) pagos com recursos públicos; c) utilizar a infraestrutura pública das universidades e institutos de pesquisa.

\section{CONSIDERAC̦ÕES FINAIS}

É inegável que a criação dos fundos setoriais, no final dos anos 1990, assim como a ampliação do financiamento para a pesquisa e para a pós-graduação contribuíram para a expansão da produção do conhecimento no Brasil, como evidenciam os indicadores da pós-graduação, da internacionalização e da produção científica hoje existentes no Brasil. Além disso, observam-se mudanças significativas nas políticas de educação superior, na expansão e na produção do conhecimento, sobretudo em termos dos fins e do modus operandi do trabalho acadêmico nas universidades e institutos públicos, o que certamente merece maior aprofundamento e compreensão.

Essas mudanças na educação superior brasileira decorrem, em grande parte, da forte expansão ocorrida nas últimas décadas. O Censo da Educação Superior de 2014 registrou que: a) 87,4\% das instituições de educação superior são privadas; b) pouco mais de $8 \%$ das IES são Universidades, porém, essas instituições detêm 54\% das matrículas nos cursos de graduação; c) a matrícula na educação superior (graduação e sequencial) superou 7,8 milhões de alunos; d) 53,2\% das matrículas estão nas Universidades; 28,6\% nas Faculdades; e 16,5\% nos Centros Universitários; e) $82,4 \%$ dos ingressantes estão em instituições privadas; f) havia 383.386 funções docentes em exercício na educação superior no Brasil e que, deste total, 57,5\% tinham vínculo com IES privada e 42,5\%, com IES pública; g) quase $70 \%$ das funções docentes nas Universidades tem o regime de contrato de trabalho em tempo integral, bem superior às funções docentes dos centros universitários $(25,5 \%)$ e faculdades $(18,2 \%)$; h) a maioria das funções docentes nas universidades tem doutorado (50,1\%), já nas Faculdades, o percentual é de $15,7 \%$; i) na rede pública, o percentual de professores trabalhando em tempo integral na universidade saltou de $74 \%$ em 2003, para 82,9\% em 2014; na titulação, 55,8\% são doutores e 28,8\%, mestres; j) das 299.355 matrículas em cursos de pós-graduação, 170 mil foram em instituições federais, $79.633 \mathrm{em}$ estaduais, 1.335 em municipais e 48.259 em privadas (BRASIL, 2014).

Considerando esse cenário, as análises mais amplas evidenciam que a globalização econômica e a acumulação do capital passam, no contexto atual, pela chamada economia do conhecimento, o 
que implica na adoção de estratégias e mecanismos que ampliem a subordinação formal e real da produção do conhecimento ao capital. No caso do Brasil, a maior parte do conhecimento é produzido nas universidades e instituições públicas e isso tem levado o Estado a implementar políticas de educação superior, de CT\&I e a mudar os parâmetros legais que alteram a relação entre o público e o privado e entre as universidades públicas, com seus pesquisadores em regime de dedicação exclusiva, com as empresas, contando com amplo financiamento dos entes públicos para esse fim.

As posições favoráveis e contrárias ao Marco legal de CT\&I denotam certamente modos distintos de compreender o Estado e seu papel na sociedade, assim como o uso dos recursos do fundo público, a relação entre entes públicos e privados, as demandas do mercado e do capital produtivo, a apropriação do conhecimento produzido nas universidades e institutos públicos de pesquisa, os fins do trabalho acadêmico, o regime de dedicação exclusiva dos professores, dentre outros aspectos. Além disso, o conceito e o projeto de desenvolvimento econômico e social apresentam diferentes matizes teóricas e políticas.

Sem dúvidas, o Marco legal de CT\&I intensificará a pressão sobre as universidades públicas, particularmente, no que se refere ao trabalho acadêmico e à produção do conhecimento. Essas instituições, todavia, precisarão exercitar mais fortemente o que garante o art. 207 da Constituição Federal de 1988, no tocante à sua autonomia, uma vez que todos os programas ou projetos previstos no Marco Legal, que impliquem na relação universidade-empresa e no trabalho dos professores pesquisadores, deverão passar por decisões colegiadas. Nesse contexto, urge discutirmos o projeto de nação e de desenvolvimento nacional que queremos produzir, o papel das universidades públicas na construção de uma sociedade mais justa e democrática e, ainda, o uso público que queremos dar ao fundo público no Brasil.

\section{REFERÊNCIAS}

ALVES, Miriam F.; OLIVEIRA, João F. Pós-Graduação no Brasil: do Regime Militar aos dias atuais. Revista Brasileira de Política e Administração da Educação, v. 30, n. 2, p. 351-378, maio/ago. 2014.

ANDERSON, Perry. As origens da pós-modernidade. Rio de Janeiro: Jorge Zahar Ed., 1999. ASSOCIAÇÃO DE DOCENTES DA UNIVERSIDADE ESTADUAL DE CAMPINAS - ADUNICAMP. Carta à presidenta Dilma Roussef, 2015. Disponível em: <http:/ /www. adunicamp.org.br/wp-content/uploads/2016/01/CARTA-DILMA-PROTOCOLADA. pdf>. Acesso em: 19 fev. 2016.

BRASIL. Lei n 13.243, de 11 de janeiro de 2016. Dispõe sobre estímulos ao desenvolvimento 
científico, à pesquisa, à capacitação científica e tecnológica e à inovação. Diário Oficial [da] República Federativa do Brasil, Brasília, DF, 12 jan. 2016.

BRASIL. Emenda Constitucional no 85, de 26 de fevereiro de 2015. Altera e adiciona dispositivos na Constituição Federal para atualizar o tratamento das atividades de ciência, tecnologia e inovação. Diário Oficial da União, Brasília, DF, 27 fev. 2015. Disponível em: <http://www.planalto.gov.br/ccivil_03/Constituicao/Emendas/Emc/emc85.htm>. Acesso em: 27 nov. 2016.

BRASIL. Censo da Educação Superior de 2014. Disponível em: < http://portal.inep.gov. br/web/censo-da-educacao-superior>. Acesso em: 27 nov. 2016.

BRASIL. Presidência da República. Plano Plurianual 2012-2015, 2012. Disponível em: <http://www.planejamento.gov.br/assuntos/planejamento-e-investimentos/planoplurianual>. Acesso em: 18 jan. 2016.

BRASIL. Ministério da Educação. Plano Nacional de Pós-Graduação 2011-2020. Brasília: MEC/Capes, 2011.

BRASIL. Plano Brasil Maior 2011/2014: inovar para competir: competir para crescer. Brasília, 2011.

BRASIL. Ministério da Ciência e Tecnologia. Fundo Nacional de Desenvolvimento Científico E Tecnológico. Fundos Setoriais: Relatório de gestão - 2007-2009. Brasília, 2010.

BRASIL. Lei no 10.168, de 29 de dezembro de 2000. Institui contribuição de intervenção de domínio econômico destinada a financiar o Programa de Estímulo à Interação UniversidadeEmpresa para o Apoio à Inovação e dá outras providências. Diário Oficial da União, Brasília, DF, 30 dez. 2000. Disponível em: <https://www.planalto.gov.br/ccivil_03/leis/ L10168.htm>. Acesso em: 27 nov. 2016.

BRAVERMAN, Harry. Trabalho e capital monopolista. Rio de Janeiro: JC Editora, 1987. BRESSER PEREIRA, L. C.; WILHEIM, Jorge; SOLA, Lourdes (Org.). Sociedade e Estado em transformação. São Paulo: Editoras UNESP; Brasília: ENAP, 1999.

CATANI, A. M.; OLIVEIRA, João F. (Org.). Educação superior e produção do conhecimento: utilitarismo, internacionalização e novo contrato social. 1. ed. Campinas: Mercado de Letras, 2015.

CATTANI, A. D. Trabalho e tecnologia: dicionário crítico. 4. ed. São Paulo: Vozes, 2008. CHESNAIS, François. A mundialização financeira. São Paulo: Xamã, 1998.

A mundialização do capital. São Paulo: Xamã, 1996.

DUPAS, Gilberto. Atores e poderes na nova ordem global: assimetrias, instabilidades e imperativos de legitimação. São Paulo: Editora UNESP, 2005.

GIDDENS, Anthony. A terceira via. 4. ed. Rio de Janeiro: Record, 2001.

HARVEY, D. Condição pós-moderna: uma pesquisa sobre as origens da mudança social. 2. ed. São Paulo: Edições Loyola, 1994.

HELOANI, Roberto. Gestão e organização do capitalismo globalizado: história da manipulação psicológica no mundo do trabalho. São Paulo: Editora Atlas S. A., 2003.

OLIVEIRA, João F.; AMARAL, Nelson C. A produção do conhecimento no Brasil e no mundo: financiamento e políticas de ciência, tecnologia e inovação em debate. In: LEITE, Denise; LIMA, Elizetg G. dos S. (Org.). Conhecimento, avaliação e redes de colaboração: produção e produtividade na universidade. Porto Alegre: Editora Sulina, 2012.

OLIVEIRA, João F. A pós-graduação e a pesquisa no Brasil: processos de regulação e de reconfiguração da formação e da produção do trabalho acadêmico. Práxis Educativa 
(UEPG. On-line), Ponta Grossa - PR, v. 10, n. 2, p. 343-363, jul./dez. 2015. Disponível em: $<$ http://www.revistas2.uepg.br/index.php/praxiseducativa/article/view/7138>. Acesso em: 27 nov. 2016.

- A política de ciência, tecnologia e inovação, a pós-graduação e a produção do conhecimento no Brasil. Inter-ação (UFG), Goiânia - GO, v. 38, n. 2, p. 323-338, mai./ ago. 2013. Disponível em: <http://www.anpae.org.br/iberoamericano2012/Trabalhos/ JoaoFerreiraDeOliveira_res_int_GT3.pdf>. Acesso em: 18 fev. 2016.

OLIVEIRA, João F.; MORAES, Karine N.; FERREIRA, A. M. A política e a cultura de inovação na educação superior no Brasil. In: CATANI; Afranio Mendes; OLIVEIRA; João F. (Org.). Educação superior e produção do conhecimento: utilitarismo, internacionalização e novo contrato social. 1. ed. Campinas - SP: Mercado de Letras, 2015. p. 127-164. 1 v.

PACHECO, Américo Pacheco. Entrevista realizada em 23 de dezembro de 2002. In: CASTRO, Maria Helena Castro (Org.) Universidade e Governo: professores da Unicamp no período FHC. São Paulo: Escuta Editora, 2003.

PEIXOTO, Maria do Carmo de Lacerda. Escola de pesquisar: estudo sobre a formação do pesquisador. 1994. 351p. Tese (Doutorado em Educação) - Faculdade de Educação da Universidade Federal do Rio de Janeiro, Rio de Janeiro, 1994.

RIFKIN, Jeremy. A economia do hidrogênio. São Paulo: M. Books, 2003.

A era do acesso. São Paulo: Makron Books, 2001.

. O fim dos empregos: o declínio inevitável dos níveis dos empregos e a redução da força global de trabalho. São Paulo: Makron Books, 1995.

SANTOS, Milton. Técnica, espaço, tempo: globalização e meio técnico-científico informacional. São Paulo: Editora Hucitec, 1997.

SANTOS, Catarina de Almeida; MORAES, Karine Nunes de. A produção do conhecimento e a Política Nacional de Pesquisa e Desenvolvimento (P\&D) e Ciência, Tecnologia e Inovação (CT\&I). Série-Estudos: Periódico do Programa de Pós-Graduação em Educação da UCDB, Campo Grande, n.30, p. 283-301, jul./dez. 2010.

SGUISSARDI, Valdemar; SILVA JÚNIOR, João dos Reis. (Org.). Políticas públicas para a educação superior. Piracicaba: Editora UNIMEP, 1997.

STIGLITZ, Joseph E. A globalização e seus malefícios. São Paulo: Futura, 2002.

TAYLOR, Frederick W. Princípios de administração científica. 8. ed. São Paulo: Atlas, 1990.

WALLERSTEIN, Immanuel. Capitalismo histórico \& civilização capitalista. Rio de Janeiro: Contraponto, 2001.

\section{NOTAS}

${ }^{1}$ A Teoria do Sistema-Mundo, de Immanuel Wallerstein, examina o capitalismo histórico e a civilização capitalista como sistema social, com destaque para as transformações produzidas pelo capitalismo mundial, com suas inter-relações, que possui forças determinantes entre os diferentes países (ricos e pobres, grandes e pequenos).

${ }^{2}$ Termo usado por David Harvey para se referir às transformações, às experiências culturais e à compressão tempo-espaço que temos vivenciado na contemporaneidade e que se encontra associado às pressões da acumulação flexível do capital. 
${ }^{3}$ Termo criado por Adam Smith para defender a economia de mercado, ou melhor, a tese de que a livre iniciativa dos indivíduos no livre mercado, em conformidade com a oferta e a procura e sem a interferência do Estado, resultaria numa ordem natural que orientaria positivamente a economia.

${ }^{4}$ Termo criado por John Williamson, economista nascido na Inglaterra, para se referir ao conjunto de recomendações de políticas econômicas por parte de instituições financeiras, sediadas em Washington D.C., a serem aplicadas na economia dos países da América Latina.

${ }^{5}$ Os fundos setoriais são administrados pela Financiadora de Estudos e Projetos - Finep. Eles foram criados, em grande parte, em 1999 (CTA - eronáutico; CT - Agronegócio; CT Amazônia; CT - Aquaviário; CT - Biotecnologia; CT - Energ; CT - Espacial; CT - Hidro; CT - Info/Cati; CT - Infra; CT - Mineral; CT - Petro; CT - Saúde; CT - Transporte; CT - Verde Amarelo; FUNTTEL - Ministério das Comunicações). Além dos fundos setoriais, o Fundo Nacional de Desenvolvimento Científico e Tecnológico - FNDCT -, instituído pelo Decreto-Lei n. 719, de 31 de julho de 1969, e restabelecido pela Lei no 8.172, de 18 de janeiro de 1991, é de natureza contábil e tem o objetivo de financiar a inovação e o desenvolvimento científico e tecnológico com vistas em promover o desenvolvimento econômico e social do País (art. $1^{\circ}$, da Lei n. 11.540/2007).

${ }^{6}$ Disponível em: <http://finep.gov.br/noticias/todas-noticias/3200-mct-agora-e-mcti>. Acesso em: 7 fev. 2016. Ver também: <http://www.brasil.gov.br/governo/2011/08/ ministerio-de-ciencia-e-tecnologia-muda-de-nome>. Acesso em: 18 fev. 2016.

${ }^{7}$ Disponível em: <http://www.planejamento.gov.br/assuntos/planejamento-einvestimentos/plano-plurianual>. Acesso em: 20 fev. 2016.

${ }^{8}$ Disponível em: <http://www.brasilmaior.mdic.gov.br/conteudo/128>. Acesso em: 18 fev. 2016.

${ }^{9}$ Disponível em: <http://www.planejamento.gov.br/secretarias/upload/arquivo/spi-1/ ppa-1/2012/mp_002_dimensao_estrategica.pdf>. Acesso em: 17 fev. 2016.

10 Mais informações em: <http://startupbrasil.org.br/sobre_programa/>. Acesso em: 20 fev. 2016.

${ }^{11}$ Disponível em: <http://www.hsn.com.br/site/startup-brasil/>. Acesso em: 15 fev. 2016.

${ }^{12}$ O Plano Brasil Maior se constitui a Política Industrial, Tecnológica, de Serviços e de Comércio Exterior para o período de 2011 - 2014, sucedendo a Política de Desenvolvimento Produtivo (2008-2010) e a Política Industrial, Tecnológica e de Comercio Exterior (2003-2007), tendo como diretrizes estruturantes: 1) Fortalecer as cadeias produtivas com "enfrentamento" do processo de substituição da produção nacional em setores industriais intensamente atingidos pela concorrência das importações; 2) Ampliar e Criar Novas Competências Tecnológicas; 3) Desenvolver as Cadeias de Suprimento em Energias; 4) Diversificar as Exportações e a Internacionalização Corporativa; e, 5) Promover produtos manufaturados de tecnologias intermediárias com consolidação de competências na economia do conhecimento natural.

${ }^{13}$ Segundo o MCT, a criação dos fundos visou, simultaneamente, ampliar e fortalecer grandes esforços da política de CT\&I, tais como: garantir a expansão e a estabilidade financeira das atividades de CT\&I; incentivar o desenvolvimento tecnológico empresarial; fomentar maior participação da sociedade nas atividades de CT\&I; oferecer um novo padrão de financiamento, adequado às necessidades de investimentos em CT\&I, gerando um novo modelo de gestão; constituir novas fontes de recursos financeiros; estabelecer estratégias de longo prazo para o todo o setor de CT\&I, bem como, definir prioridades focadas em resultado (SANTOS; MORAES, 2010). 
${ }^{14}$ Disponível em: <http://geocapes.capes.gov.br/geocapes2/>. Acesso em: 22 abr. 2016.

${ }^{15}$ Cabe lembrar também que a Coordenação de Aperfeiçoamento de Pessoal de Nível Superior (Capes), vinculada ao Ministério da Educação (MEC), e o Conselho Nacional de Desenvolvimento Científico e Tecnológico (CNPq), vinculado ao MCTI, foram criados em 1951, por ocasião do governo Getúlio Vargas (1951-1954). E, também a criação do Fundo Nacional de Desenvolvimento Científico e Tecnológico (FNDCT), e a aprovação do Plano Básico de Desenvolvimento Científico e Tecnológico I, II e III.

${ }^{16}$ Mais informações em: <http://www.senado.gov.br/noticias/Jornal/emdiscussao/ inovacao/projeto-de-lei-codigo-ciencia-tecnologia-e-inovacao/projeto-de-um-codigonacional-de-ciencia-para-incentivo-a-empresas-e-pesquisadores-para-desenvolvimento-deciencia-tecnologia-e-inovacao.aspx>. Acesso em: 20 fev. 2016.

${ }^{17}$ Sobre esse tema foi aprovada, recentemente, a Lei 13.123/2015. Disponível em: <http://www. planalto.gov.br/ccivil_03/_Ato2015-2018/2015/Lei/L13123.htm>. Acesso em: 20 fev. 2016.

${ }^{18}$ Disponível em: <http://www2.planalto.gov.br/acompanhe-o-planalto/discursos/ discursos-da-presidenta/discurso-da-presidenta-da-republica-dilma-rousseff-durante-acerimonia-de-sancao-do-marco-legal-da-ciencia-tecnologia-e-inovacao-e-lancamento-dachamada-universal-brasilia-df>. Acesso em: 20 fev. 2016.

${ }^{19} \mathrm{O}$ Plano Inova Empresa foi lançado em 14 de março de 2013 pela Presidência da República, com R\$32,9 bilhões de dotação. Cf.: http://www.mct.gov.br/upd_blob/0225/225828.pdf. Acesso em: 20 fev. 2016.

20 Sobre a Embrepii, conferir: <http://embrapii.org.br/>.

${ }^{21}$ Disponível em: <http://www2.planalto.gov.br/acompanhe-o-planalto/discursos/ discursos-da-presidenta/discurso-da-presidenta-da-republica-dilma-rousseff-durante-acerimonia-de-sancao-do-marco-legal-da-ciencia-tecnologia-e-inovacao-e-lancamento-dachamada-universal-brasilia-df>. Acesso em: 20 fev. 2016.

${ }^{22}$ Mais informações em: <http://www.mcti.gov.br/noticia/-/asset_publisher/ epbV0pr6eIS0/content $/ \% \mathrm{E} 2 \% 80 \% 9$ Choje-e-um-dia-marcante-para-o-futuro-dobrasil $\%$ E2\%80\%9D-diz-dilma-sobre-marco-legal-da-ct-i>. Acesso em: 20 fev. 2016.

${ }^{23}$ Disponível em: <http://www.adunicamp.org.br/?p=1884>. Acesso em: 19 fev. 2016.

Submetido: $26 / 03 / 2016$

Aprovado: 24/08/2016

Contato:

João Ferreira de Oliveira

Rua 1042, Qd.113, Lt.18

Setor Pedro Ludovico

Goiânia|GO|Brasil

CEP 74.825-090 
